\title{
From intersubjective situations and personality problems to a new vision and reality
}

\begin{abstract}
The article considers one of the mechanisms of creativity and development. The following hypothesis is advanced: the existential problems of the individual, find their solution in a new vision, which is initially incomprehensible and unacceptable, but then is understood, i.e., interpreted and schematized and therefore becomes understandable. To confirm this hypothesis, five cases are analyzed, the concepts of vision, reality, and existence are discussed, and the author's conception of the dream is used.
\end{abstract}

Keywords: vision, reality, situation, creativity, development, scheme, cases, problems, realization, personality
Volume I Issue 2 - 2017

Rozin Vadim Markovich
Institute of Philosophy, Russia

Correspondence: Rozin Vadim Markovich, Institute of Philosophy, Russia, Email rozinvm@gmail.com

Received: September 26, 2017 | Published: September 29, 2017

\section{Introduction}

The article describes one of the mechanisms of creativity and development. It puts forward the following hypothesis: the existential problems of identity, find their resolution in a new vision, which is initially incomprehensible and unacceptable, but then conceptualized, i.e. interpreted and schematized and consequently becomes clear. To confirm this hypothesis examines five case studies, discussed the concept of the vision of reality, the existence, the author uses the concept of dreams.

In the seventh letter, Plato writes that the acquisition of true (consistent) knowledge presupposes, on the one hand, the appropriation of a name, the construction of definitions and images, on the other hand, reasoning's and benevolent discussions, and if these two conditions are met, then "knowledge of what a person is looking for." All this must be considered as one thing, since it does not exist in sounds or in bodily forms, but in souls... Only with great difficulty, through mutual verification- by name by definition, by visible imagesby sensations, and besides, if it takes place in the form of a benevolent study, with the help of non-malicious questions and answers, the mind can be enlightened and an understanding of each subject can be born to the extent that it is available to man". ${ }^{1}$

Here it is interesting what Plato means by saying "to shine"? Maybe what the phenomenologists talk about? "The phenomenological method," PP Gaidenko's important note makes an important point, "cannot deal with a reality that is not fundamentally, cannot become a phenomenon, in that it is itself a consciousness". ${ }^{2}$ One can recall the founder of phenomenology, E. Husserl, who wrote in "Logical research": "I cannot force anyone to clearly see what I see. But I myself cannot doubt, I again, with self-evidence, realize that any doubt where I have evidence, that is, where I directly perceive the truth, would be absurd ...'If we stick to the above-mentioned concept of truth, then the truth as the correlate of the identifying act, there is some substantive content, but as a correlate of complete identificationidentity: the complete agreement between what is meant and the data as such. This consent is experienced in evidence, since evidence is the actual fulfillment of an adequate identification."

Evidence, "comments Gaidenko on these statements," thus, there is, according to Husserl, the immediate experience of truth as concord, the coincidence of the intentional content of the act of consciousness with the objective content, the objective reality-the state of things (Sachverhalt) ... in Husserl, perception is the basic mode of consciousness as the condition of the possibility of all other modes: for in the perception the being of the object is directly revealed; What we call perception on the part of the subject, on the part of the object corresponds being. In this-a kind of empiricism of phenomenology, peculiar because it is very different from empiricism of the XVII-XVIII centuries and comes closer to intuitivism (let's not forget that Husserl has in mind the perception of pure phenomena, and not empirical phenomena)". ${ }^{2}$ Of course, Plato did not know anything about phenomenology, but, nevertheless, the situations seem to be similar: in both cases it is about cognition, and here and there it ends with the discovery of a new objectivity, which is given in the form of a special vision of reality (for Plato, eidos, for Husserl's intentionality). I can add to that what I have said about my experience of scientific creativity. Often after a long search for the solution of the problem, suddenly, as if a third eye opened, you begin to see both the solution and, most importantly, the new reality.

The feeling that I got into a new world, where everything fell into place and is understandable. I will only pay attention to the fact that Plato, though in passing, notices that "beamed", we need a benevolent discussion, that is, as we said today, the intersubjective situation, "other", "special communication". In this regard, we can assume that the whole for Plato is not the act of cognition itself. In Husserl, perhaps, consciousness exists in itself, it is the whole. So, one context for the phenomenon of a new vision and object is cognition, but probably there is another -the realization of the person, for Plato in each of his dialogues realizes himself, for example, in the "Feast" he resolves his three and at the same time general cultural problems: he gropes the way for the right life, leading to salvation, gives definitions of love that allow one to love the becoming of an ancient person, receives a consistent knowledge of love and salvation. ${ }^{3}$ However, a person can realize himself not only in cognition, and as analysis shows, he can again to open a new vision and reality. Here, the case, which I love because of the wealth of meanings that can be extracted from it. The first is the teenage memory and experience of K. Young. Once, on a beautiful summer day in 1887, admired by the universe of Jung, he thought: "The world is beautiful and the church is beautiful, and God, who created all this, sits far away in the blue sky on the golden throne 
and ... Here my thoughts broke off and I felt choking. I was numb and remembered only one thing: Now do not think! Something terrible comes. (After three heavy from the inner struggle and the experiences of days and sleepless nights, Jung still allowed himself to think up what he had started and seemingly innocuous thought).

I gathered all my courage, as if I suddenly decided to jump into hellfire immediately, and gave the thought of the opportunity to appear. I saw before me the cathedral, the blue sky. God sits on his golden throne, high above the world - and from under the throne a piece of feces falls on the sparkling new roof of the cathedral, breaks through it, everything collapses, the walls of the cathedral are broken into pieces. That's it! I felt an unspeakable relief. Instead of the expected curse, grace has descended upon me, and with it an unspeakable bliss I never knew ... I understood many things that I did not understand before, I understood what my father did not understand-the will of God... Father accepted the biblical commandments as a guide, he believed in God, as prescribed by the Bible and as taught by his father. But he did not know the living God who stands free and omnipotent stands above the Bible and over the Church, which calls people to become as free. God, for the fulfillment of His Will, can make his father leave all his views and beliefs. Experiencing human courage, God forces us to give up traditions, no matter how sacred they are ". ${ }^{4}$

We will comment. The first question that arises here is why Jung believes he has learned the will of God. The material of memories allows us to answer this question. At that time young Jung was occupied with two problems. First: the relationship with the father, a hereditary clergyman. According to Jung, the father dogmatically fulfilled his duty: having religious doubts, he did not try to solve them, and in general was not free with respect to the Christian Faith. The second problem: building your own relationship with God, understanding the attitude towards the Church. A little later than the episode in question, these problems were resolved by Jung, and crucially: he breaks up, spiritually, with his father and the Church. After the first communion, Jung comes to a decision, which he formulates as follows.

"In this religion, I no longer found God. I knew that I could never take part in this ceremony again. The church is a place where I will not go any more. There everything is dead, there is no life. I felt pity for my father. I realized the tragedy of his profession and life. He fought death, an existence he could not admit. Between him and me there was an abyss, she was boundless, and I did not see an opportunity to ever overcome it ". ${ }^{4}$ This is the direction in which Jung evolved: without realizing it, he went to a break with his father and the church. And, this despite the fact that Jung received religious education and believed in God. To decide on the gap, Jung needed support, both semantic and personal. But who could support Jung, when he breaks both with his father and with the Church? Objectively, as we understand, the only support for Jung is he, or, as he later said, "His demon." Subjectively, the case looks different: only God can help, however, not the one about which the church and the pastor-father are talking about. And then, Jung composes his God, God, who looks like a real revolutionary, God, prompting a decision-to break both with the church and with his father.

This observation can also be extracted from this case: first comes the phase of a new vision (Jung saw an incomprehensible picture of God's destruction of the church and how a man brought up in the Christian faith was terribly frightened), then a phase of comprehension stretching for three days, as a result of which Jung created an interpretation, (let's call the first phase "paradoxical", why so, it will be clear from the following, the second phase - "comprehension"). But the vision was not accidental: it induced Jung's thought in a very definite direction. Can we then formulate the following hypothesis: the existential problems of the personality caused by intersubjective situations find their solution in a new vision that is initially incomprehensible and unacceptable, but then is understood, i.e., is interpreted (schematized) and therefore becomes understandable. And here is another case that confirms this hypothesis.

\section{The second case is the case described by $\mathbf{N}$. Berdyaev}

"Akimushka told me one day about the extraordinary event that happened to him when he was a boy. He was a shepherd and herd. And suddenly he had an idea that there was no God. Then the sun began to fade, and he plunged into darkness. He felt that if there is no God, then there is nothing, there is only perfect nothingness and darkness. He seemed completely blind. Then, in the depths of nothingness and darkness, suddenly the light began to light, he again believed that there was a God, "nothing" turned into a world brightly lit by the sun, everything was restored in a new light". ${ }^{5}$

At first Akimushki's fantasy articulated in the sentence "There is no God" (only two words, but what!) Gave rise to reality, in which there was no place for either the sun or the life of the boy himself. Then, probably, the personality of Akimushka, saving herself, created a sunlit world and the assertion that "God is." It is unlikely that Akimushka's imagination was accidental: she answered some of his deepest doubts; they are resolved in a new vision - darkness, which becomes clear after the creation of a special scheme ("if there is no God, then there is nothing, only perfect nothingness and darkness"). If the proposed hypothesis is correct, then it is necessary to answer a number of questions: what is a new vision, how it arises and what is conditioned, what role is played by the composition (invention) of schemes and interpretations, due to which understanding develops and what is it? Let's continue the research on the same way of case analysis. The third case is the opening of the image by the child.

The adult draws a red round spot on the paper and says, pointing to it: look Masha, what a sun. But it turns out that at first Masha does not see any sun. By the way, it is understandable why: the sun is in the sky, shining, blinding, warming, and here paper and a red spot. However, later, for some reason Masha begins to see on the paper the sun. The following scene, for example, could prompt this discovery. In the evening, at sunset Masha's father shows her the sun and says: how beautiful, the sun sets. Suddenly, Masha notices that the sun at sunset is very much like a red round spot on paper. And then there is what can be called the "effect of form". On the one hand, drawing a red round spot, Masha looks at him, remembering the sun at sunset. On the other hand, it starts to perceive the "red spot against the background of white paper" as the sun, but something that is not in the sky, does not blind and does not heat, but which you can create yourself (draw), and as you want and for an interesting pastime . For example, draw a red spot and say that the sun has come to Masha, it will warm the grass, walk through the sky, etc. In this case, the role of the "picture sun" is not to really be in the sky, shine and warm, but in that to Masha play and talk, to communicate about the sun, to live in this new interesting world.

Summarizing this example (naturally attracting others), it is possible to introduce such distinctions. First, existential problems of the individual, requiring their solution. Specifically for Masha, when she has not yet become acquainted with the image, this is the desire 
to see the sun on paper, which she does not see, although her dad for some reason sees it. Such a desire is very natural and important for the child. Living with his parents, not separating himself from them, which Vygotsky denoted with the term "prama", a small child tends to live and live (see, hear, feel what his parents say, if dad says, pointing to a red spot - this is the sun, then it must necessarily be there). For Jung-it is an unconscious desire and a problem to break with the church and father.

Secondly, there is such a phenomenon as the discovery of a new form (the sun at sunset, the red spots on the background of paper), which in the semiotic sense can be understood as a scheme. The new form, which follows from further events, allows you to cope with the existential situation (see the sun on paper), opens a new vision (the image of the subject in the drawing), allows you to react in a new way (to communicate and play based on the image).

One of the conditions for the invention of the scheme is the awareness of the features of the form or its construction (not the sun and the red spot, but the sun against the sky, a round red spot drawn on paper). Other necessary the condition is the discovery of a new objectivity (in this example, the opening of the picture sun, it does not live on the sky, but on paper, it does not shine and does not heat, it can be painted, it is interesting to play with it, or God Young, which destroys the church). What does "detection" mean in this case? Psychologically, it is likely that reorganization is based on the creative effort and scheme of the individual's psychic experience, as well as the act of realizing the existence, reality (naturally in the form and form that are available to him). Without the awareness of the picture sun, i.e. discovering it in the world, naming (this need was pointed out by Plato), awareness of its difference from related objects (the picture of the sun is somewhat different from the ordinary sun)-a new objectivity can not appear. It's not easy to explain how an individual expresses all these aspects of the emergence of a new objectivity. Another condition, more precisely the premise is the inclusion in a new whole (switching the whole). Indeed, so that Masha could open the drawing sun and start living with him (drawing, playing, communicating with others about it), she had to switch to the problem of relationship with her father (since he says the sun, it should be so, here the existence and communication within the framework of the pram coincide), the situation of admiring the sunset (also, by the way, intersubjective, as it requires a response), the reality of the game and communication. For Jung, this was probably a new life, where he could deny the sacred realities and act independently; as a person.

All the moments listed here form the basis for the formation of a new reality that allows an individual to resolve certain existential situations and live fully. Comparison of the third case with the second makes it possible to clarify the initial hypothesis. These two phases (paradoxical, i.e., the discovery of a new vision, and the comprehension that involves schematization) looked like independent of each other and following in time one after another (first the first and then the second). In fact, the second phase largely determines the first phase. Indeed, it was the desire to break with the church and father that determined both Jung's unintelligible vision and the sophisticated scheme-interpretation of the revolutionary God. Probably, Masha watched more than once, how her parents draw, and perceived this occupation as an interesting game. The latter initiated a desire to also play this game, and also strengthened the installation to see on paper the sun.

It seems that in both cases the new vision is a purely visual phenomenon (Masha sees the red sun, and Jung does not have God throne sending the need to the roof of the church cathedral). But we will think over the content of visual images that appeared after the second phase of comprehension. The sun, which is not in the sky, does not dazzle and does not warm, but can be painted, can walk in the sky and illuminate the earth and grass, not by itself, but with the help of the Machine words-such suns are not seen by ordinary eyes, but rather understood ; is it not called the "third eye" like "vision-understanding." Thus, I propose to distinguish between a purely "visual image" and an image formed in the context of vision-understanding (let's call it "mental"). It can be assumed that the mental image is formed within the context and context of the reality of the second phase. We note that these two cases (cognition and play) do not exhaust the types of the second phase; comprehension unfolds in other practices, for example, in communication, art, and practical activities (whose types are also plural) and in others.

But what, after all, is a new vision in the paradoxical phase, and what exactly does a person see here? We ask when we see not usually and often paradoxical events and things? Of course, in a dream. I will make a digression in order to characterize the nature of sleep. In him I distinguishthreepersons. Thefirsthypostasisofthedreamistheautomatic unconscious realization of blocked programs of human activity. The fourth case.

I have to make a report, prepare for it, but the report was unexpectedly postponed. Sometimes, in this case, I dream that I'm still doing this report, or that I'm making a report, and it's interrupted, or that I can not start the report, I forgot its text, although the listeners are already waiting - there are not any options to consider. What does it mean "prepare for the report"? I am attuned to certain events: I need to understand what ideas I will come out with, how to submit them, how to take into account the understanding and misunderstanding of listeners, where I will begin, how I will lead the listeners, than I finish, what will be the possible reaction to my report, In this case I will respond, etc., etc. I am adjusted to certain events; I experience them, although they have not yet been actualized. But the fact is that since a person is a semiotic being, he loses events in the language and imagination (they are captured by them) even before they can be actualized. This is what I call the programming of human activity. Then there are two options. I actually make a report and my setting (program) breaks up, disappears; we call the process of disintegration and disappearance of the program "implementation." The second option - I for some reason can not make a report. We will call this case after psychologists "blocking the program." Judging by experiments on interrupting dreams, programs must necessarily be implemented; otherwise they first create tension in the psyche, and then lead to its destruction, then to the death of the body.

A psychic to continue working (after all, a person is involved in all new and new situations), removes blocked programs, temporarily transfers them to another floor of the psyche. In the period of sleep, she returns to these programs to implement them. But this is not a dream, but an automatic work of the psyche, of which we know nothing, because in our dream consciousness is off, does not work. And since there is no consciousness, then vision and memory do not work. To see something, even a dream, it is necessary to be aware of what is happening. But in a dream consciousness is turned off, so we do not realize anything. It is to this case that the expression "he slept with a deep, dreamless sleep".

Now a difficult question about what constitutes blocking programs. To answer it, you need to better understand what perception is, let's take visual for example. The usual view that all visual information 
necessary for a vision is contained in the object (space) under consideration, the role of the human psyche is only in the processing of this information after it passes through the eye. However, there are psychologists who also share this point of view. Thus, JJ Gibson and EJ Gibson argue that the person's eye gets about the subject all the necessary information (visual stimulus at the entrance, they say, contains everything that is available in the visual image). It is another matter that in some cases the eye is able to master all this sensory information, while in others it loses a significant part of it due to ineffectiveness of its activity, underdevelopment of visual abilities of discrimination, differentiation, etc.

The opposite point of view was outlined at the end of the last century by H. Helmholtz and then deepened by modern experimental psychologists. Briefly, its essence is that only a part of the visual information comes from the subject, while the other (of a different nature) is brought by the person himself. What a person sees is the result of the merging of visual impressions of the object and the counter activity of the person sending out the clots of past experience, meaningful and meaningful, integrated into the general structure of human consciousness. To the indicated point of view of the researchers resulted various observations on visual perception, as well as specially set experiments.

It is from the material of the previous experience of perception (not only visual, but also sonorous and tactile) that our psyche builds "events" during the sleep period necessary for the implementation of programs and plans for blocked activities, as a result of which they decay. This process-the construction of "events" that provide the implementation of blocked programs and forms the material basis of dreams. I put the term event in quotes to emphasize that it is not actually the events that we see in the dream, but only their substrate base. Events are a construct of consciousness, and it is turned off in the first hypostasis of dreams. Events in quotes resemble the Kantian thing in itself: we can not say how they are arranged, but we can think of them.

Events in quotes, we call them "substrate-events" is the material premise of these events in the second incarnation dreaming. But for the implementation of blocked programs, it is enough just the substrate-events. The second hypostasis of the dream is the process of dreaming. Although the processes of implementing such programs and plans play an extremely important role for the mental health of a person, they are usually not realized. They are realized in those cases that form the second hypostasis of dreams, when our consciousness for some reason is not completely turned off. Typical cases here are.

We fall asleep or wake up, our psyche switches the body to sleep or to wakefulness; while the consciousness passes the phase from fullfledged work to a kind of paralysis. At these transitions, consciousness is not fully involved: perception and reason are turned off, memory functions are violated, and emotions are altered. The second case is no less characteristic: it is formed by various strains - overwork and over excitations, diseases with temperature, strong seizure by activity (for example, we can not stop and stop solving problems of interest), and finally, taking alcohol or drugs.

In all such situations in the period of fast sleep (that is, the implementation of blocked programs), our consciousness is only partially involved, but it is enough to bring us into a completely new world, a "dream reality". In this case, the psyche from the material of the previous experience (events in quotation marks) constructs not only the actions and experiences themselves, but also the subject that implements them, that is, creates the "dreamy I". And the fact that we have experience that allows us to design such a character, I think, is beyond doubt. This is the experience of our awakening (I find myself, I collect, I put in the flow of time, I feel my body and so on), the experience of feeling myself in different situations of life. Based on this experience, the psyche in the period of fast sleep creates a dreamy self. This I, of course, is very different from our usual.

A dreamy I possess only those properties that are necessary for implementing blocked programs. For example, in a dream, we absolutely do not need reason, criticism, moral considerations, and the like, things that are necessary in ordinary life, they would in turn block the implementation of blocked programs. But everything else that is necessary for realization, the psyche attracts: finding you in a dreamy world, feeling yourself, centralizing experiences and so on. Almost the main feature of the dream events is their independence from our ordinary I, with his reason, criticism, criteria of reality. In order not to happen in the dream, we are not surprised, but perceive, as the most common thing. Sometimes, though, on the periphery, I catch myself in some slight perplexity, but I think that our ordinary self is already invading, that is, I begin to wake up.

The third hypostasis is the comprehension of dreams. Beginning to explore the dreams, Valeri Podoroga establishes the initial fork: "between the dreams seen, that is, the" picture "- the dream in itself and for- myself, and the dream narrated, "History" - a dream for another ". And then he asks the following question: "Is it not possible that we wake up after we have already interpreted a number of signs that seemed to be dreaming? We did not really dream, but in a dream we experienced certain states that we consider a dream, and we are sure that we dreamed a dream ... But did we dream? Perhaps there is a field of instant authenticity of the experience that does not correspond to any "vision" in a dream, for it is the action of our "fast" memory, so similar to the first trial interpretation ". 6

I think Podoroga is right. What he calls "certain states" are dreaming events in the dream reality, but, really, only after passing through the phase of comprehension and interpretation, the dream events allow us to build up the dream event itself to our waking consciousness. Falling into a fully awakened waking consciousness, the dream events in the sequence that was remembered (we will not forget that the memory in the dream reality is also working halfway and not quite as usual), they supply the material for comprehension and interpretation. On this basis, within the framework of the conceptualization accepted by the person (that is, the way a person understands what a dream is), the psyche also gives rise to the events of dreams, thus completing the first cycle. The next is the rethinking and thinking over the dream. In other words, we call the dream the end result of the three phases of the dream - the realization of blocked programs, the construction and unfolding of the dream reality and the comprehension of its material in a waking state. Moreover, the first two phases go simultaneously, and the third goes after them (see details of all three hypostases). ${ }^{6}$ Let's return to what we learned about our topic. Does not the process of opening a new vision to the logic and structure of the dream? In part, namely in terms of implementing blocked programs. The difference is still significant. In a dream, blocked programs are conditioned by situations and plots of ordinary life, and the phase of the comprehension of dreams follows the first two. In our cases, these programs are caused by at least three other points. 
First, the existential problems of the individual; their source, as we have shown, is twofold: on the one hand, these are intersubjective situations, on the other - their subjective mastering by the individual. Secondly, in this case, the blocked programs, as related to the paradoxical phase, are conditioned by the pressure of situations of comprehension, and in different ways in cognition, play, communication, etc. Thirdly, there is a certain material for the embodiment of the past experience of perception (in Jung, this is his relationship with his father and church, as well as God with the church, Masha-the usual sun and a red spot on paper).

The difference is that our heroes do not sleep, and, consequently, their thinking does not follow the implementation of blocked programs, but in parallel with it and, as already noted, is conditioned by different contexts and practices. Finally, there is another significant difference: the dream psychic acts unconsciously, and the subjects we are interested in are not simply in full consciousness, but, so to speak, forced to creativity. In the case of Jung, this is particularly revealing: in order to solve his dilemma, he composed a rather complex plot. And Akimushka, in order to see clearly, is constructing a difficult conclusion: "if there is no God, then there is nothing, only perfect nothingness and darkness." Let's analyze the logic of this creativity in more detail. What is the problem situation? On the one hand, there are old structures that can not be discarded. Jung can not stop believing in God, and Masha cannot see that the real sun and the red spot on the paper have nothing in common. On the other hand, the problem situation sets new content - Jung's desire to break with the church and father, for Masha, see the sun on paper - and these contents can not be seen and thought. It seems a complete impasse. But Masha notices that the sun at sunset is very similar to a red spot on the background of paper. In turn, Jung comes to the idea that since God is omnipotent and free, he can do everything, even the most incredible, contrary to the Bible and the Gospel. The discovery of these "intermediaries" and these are real mediators, suggesting "bridges" between new and old structures and content, allows our heroes to take the next creative step-to build a scheme that finally resolves the problem situation. A powerful and free God destroying the church, and the sun at sunset, identified with a red spot on paper, not only allow old and new structures to exist, although, by limiting their territory to certain cases, they also resolve the problem situation by opening the door on the one hand, in an event fraught with serious consequences, on the other-in the game.

Well, from the point of view of substrate reinforcement, the psyche probably builds a hallucination (a dream in reality), which is perceived as a vision of a new phenomenon (the sun on paper and God destroying the church). However, the evolving hallucination is not an independent hallucination, it does not form a whole; the whole is given by a problem situation, intersubjective contexts, the creativity of the individual, including the invention of intermediaries and schemes. Another plan for the opening vision, concluding the first phase, without which a new phenomenon could not take place-the constituting of existence. To clarify, I will bring one more case.

\section{The fifth case is a case from the author's life}

After graduating from school, I could not enter the MEPhI and went to work as a fitter at a military plant. I took a bed in a Jewish family, where my grandfather arranged me. In the room, apart from me, there were three other men, meteorologists, who had come to retraining courses. Their sleep was upset once and for all because of the professional way of life. At night they woke up, lit up the light, talked about life and smoked so much that because of the smoke of the cigarettes there was no light bulb visible. Probably, I was overtired, for several days already I did not wake up from a fully wound up big alarm clock, more precisely woke up exactly five minutes after call. In this state, still not quite awake, I went to work at one o'clock in the morning. It was completely dark. When I began to cross the line of the train, I saw a train leave the station. His searchlights powerfully cut the darkness, and suddenly, I was stupefied. In the light of the headlights of the train much faster than she moved, the devil ran. He was huge, about 5-6 meters, all black with a long tail. My heart stopped beating with fear, I stood there in my tracks.

The devil ran to the nearest openwork post, on which power wires hung, instantly scrambled over it and disappeared in the dark. I still remember what was happening to me. I could not believe my eyes; I saw the devil as clearly as the surrounding darkness or the train. I also clearly remember my fear. And I could not believe in what I saw either: the devil does not exist, but in God I never believed. I acted, as I understand now, quite wisely. More precisely, I did not act, but probably triggered the mechanism of self-preservation: that "the roof did not go", I just put aside all that had happened to the best of times. I did not begin to explain why I saw the devil, but I did not deny this fact. I think, if I compare my experiences with Jung's experiences, there will not be much difference. And there and there a clear vision of a phenomenon that can not exist. And yet it is there, and consequently, somehow exists: exists in the form of the impossibility of existence (let's call this existence "paradoxical" and remember how I called the first phase). Is the existence of the sun on paper, for Masha, and the world without God, for Akimushka also paradoxical? Nevertheless, the paradoxical existence is still existence: yes, we do not understand what it is, but since the phenomenon is obvious, we have to recognize its being, albeit in an indefinite status. Jung took three days to realize the second phase - to comprehend and understand what he saw.

I'm thirty years old to understand what I saw that night, frightened by the devil. Having built the theory of dreams in the early 80 's, I came to the conclusion that I had a hallucination. I'll do another digression, to explain the relationship of dreams and hallucinations. What happens if a person does not have the conditions for implementing blocked programs, for example, does not sleep a few nights? In other words, if the very possibility of implementing blocked programs is blocked. In his psyche, unrealized programs that create stresses accumulate. Sooner or later they begin to determine the basic mental processes, as well as events that are recognized by man. In principle, here we can distinguish two different cases - a "dream in a dream" and hallucinations.

The general mechanism here is this. First, blocked programs that can not be implemented, as if gaining strength, their "psychobiological potential" (we introduce such a notion) increases. From a certain point, blocked programs begin to be implemented in parallel with the implementation of other programs in an unusual, one might say forbidden for blocked programs, the area-in wakefulness. At the same time, they fall under the floodlight of a fully engaged consciousness, which in principle does not allow the events of blocked programs. The first trick of the psyche is to disguise illegal events under the guise of events of ordinary life. A simple example. After a sleepless night, we can not concentrate on our current work in any way. About something we remember, we are distracted, we are going through some extraneous subjects. All this is nothing more than the contraband eradication of blocked programs, which, in principle, takes place in 
the form of wakeful life activity. The psychic stealthily manages the mind, slipping aside extraneous subjects and memories. As a result, consciousness can not recognize blocked events and misses them. Let us emphasize that "sleeping in reality" is, of course, no dream, there is no phase of dreaming events.

If the psychobiological potential increases even more (the second case), then the psyche ceases to engage in mimicry. She is forced to implement blocked programs as soon as possible. As a result, they get the status comparable to the usual current programs, which are implemented "here and now". How can consciousness recognize and master blocked events, because they, in his view, are illegal? Only conceptualizing them, just like illegal mental entities. In this case, we are talking about hallucinations, that is, about what is not really.

Which is generally not true? Hallucinosis events, of course, are not in the sense of the reality of our consciousness, but they are real and necessary in terms of the work of our psyche. For example, if there were normal conditions, and consciousness was turned off in part, the events that led to hallucinations would take the form of events of dream reality. The devil I saw that night was a complicated hallucination. Now, many years after this event, it is almost impossible to even roughly interpret what blocked programs (desires and fears) gave rise to such a hallucination. But there is material for our topic. As a result of the study of dreams, I managed to change the paradoxical existence of the phenomenon to exist, so to speak, normal. And Jung was able to come out on a normally existing phenomenon in three days (God as a revolutionary, of course, existed only for Jung, for example, for the church such existence of the Creator would be clearly paradoxical). Interestingly, and more.

Characteristics I did not get at all from observing the devils (and even where I could observe it, unlike, say, Emmanuel Swedenborg, who claimed that he had many times spoken with angels and demons). ${ }^{7}$ These characteristics I introduced, explaining what happened to me in the theory of the dream. In other words, the second phase (comprehension and schematization) for me was humanitarian cognition (humanitarian, because I built my dream concept, consciously pursuing my own values and trying to retain the uniqueness of my mental work). ${ }^{8}$ Thus, the trait, which I comprehended, having received a mental image, was the ideal object of the humanities. ${ }^{9}$ For Jung, the God-revolutionary belonged not to the sphere of knowledge, but to an ethical act. I will not repeat, in both cases for comprehension of paradoxical existences creativity and schematization were necessary.

In addition, understanding involves three more types of work. First, the elimination of those features and characteristics of objectivity, which were not needed in new contexts (practices). For example, the picture sun, unlike the present not in the sky, does not blind and does not heat. As a result, Masha, while painting, ceases to expect these characteristics. It can not be said that they are removed in the drawing at all, no, they remain, but they are used in another role, namely, the language values (operators) that are played. Likewise, Jung's Godrevolutionary is not at all like the ordinary Christian God, the main characteristics of the last Jung were not needed.

Secondly, the emerging new objectivity, so to speak, acquires new properties and characteristics that are necessary for life in the new reality. The drawing sun needs to be drawn, i.e. it is artificial and man-made, it must be placed in the picture (it is only an element of the whole), it must be made live - to walk across the sky, to warm the earth, to illuminate houses and people, etc., in addition to the drawing itself, verbal accompaniment is necessary (all these unusual characteristics of the sun Masha needs to invent). Accordingly, Godrevolutionary Jung attributes such an important characteristic as an act of destroying the church. It is clear that such an act would not be completely characteristic of the Christian God.

Thirdly, the emerging objectivity is sooner or later endowed with signs of a new, non-paradoxical existence. This act is particularly interesting. On the one hand, defining the feature I saw many years ago as a hallucination, I get the opportunity to attribute to it many new characteristics, taken not at all from observing the phenomenon, but from the ontology of the humanities. Once a hallucination, this is one of the types of dreaming in real life, this is due to the impossibility to realize the blocked desires in the usual way, in reality hallucinations can not match anything; their source must be sought in the way of life of the person, etc. etc. Describing God as a free person and a revolutionary, Jung also has the opportunity to attribute to him many new properties: such a God can go against tradition, make a revolution; he does not fear anything, etc. On the other hand, the actualization of existence involves building up oppositions with other kinds of existences and realities. Masha's pictorial sun exists in the game and artistic creation, which are opposed to other types of life and activities (ordinary life, travel, study, and sleep).

It's another matter how Masha realizes these oppositions. Typically, this awareness goes through several stages, often leaving for adulthood. For example, already in his adult state, Jung realizes his God within the esoteric reality. "But there was," he writes, "and another world, and he was like a temple, where everyone forgot himself, with surprise and delight comprehending the perfection of God's creation. In this world I lived my "Other", who knew God in himself, he knew him as a secret, although it was not only his secret ... "Another", "number 2" is a typical figure, but it is realized by few ... the world of my second "I" was mine, and yet I always had the feeling that in that second world something was involved besides me.

It was as if the whiff of huge worlds and endless spaces touched me, as if an invisible spirit was flying into my room - the spirit of someone who has not existed for long, but who will always be who exists outside of time ". ${ }^{4}$ Apparently, with this worldview, Jung had messianic ideas too. Jung believed that all his works were some kind of errands, they were written according to the dictates of fate, according to the dictates from above. "By me, wrote Jung, a certain spirit that spoke for me" took possession ". ${ }^{4}$ Jung was not alien to the ideas of esotericism, that is, he critically perceived this world and believed in another world as a true reality.

"Then the possibility of the existence of another reality," he writes, "becomes an unavoidable problem, and our world, with its time, space and causality, with itself, or under itself, hides a different order of things where" there "does not exist, and" there "," earlier "and" later "" [153, p. 300]. It is not difficult to understand how many characteristics and meanings Jung could attribute to his God within such a rich ontology.

If we now ask what type of existence can be attributed to the phenomenon analyzed here, then my answer is this: one of the mechanisms of creativity and development was singled out and described in the first approximation. Indeed, do creativity and development start from intersubjective situations and subjective problems, do they not presume in addition to searching and 
implementing a certain methodology a new vision, schematization and a number of other procedures, are they then completed as a whole by the assumption of existence and the discovery of a new reality? I answer this question positively with this work.

\section{Acknowledgements}

None.

\section{Conflict of interest}

The author declares no conflict of interest.

\section{References}

1. Plato. Seventh letter. Plato Treatises, speeches, letters. 1994. 175 p.

2. Gaidenko. Breakthrough to the transcendental. A new ontology of the twentieth century. 1997.
3. Rozin VM. "Feast" of Plato. New reconstruction and some reminiscences in philosophy and culture. Moscow, Russia; 2015. 200 p.

4. Jung K. Memories, dreams, reflections. Kiev, Ukraine; 1994.

5. Berdyaev N. Self-knowledge (experience of philosophical autobiography). 1990.

6. Rozin VM. The nature and genesis of European art (philosophical and cultural-historical analysis). 2011.

7. Rozin VM. Demarcation of science and religion. Analysis of the teachings and creativity of Emanuel Sveedborg. 2007.

8. Rozin VM. Features of discourse and research in the humanities. 2009.

9. Podoroga V. Code of the Dreamer. The Facets of Knowledge: Science, Philosophy. Culture in the 21st Century. Russia; 2007. p. 282-283. 